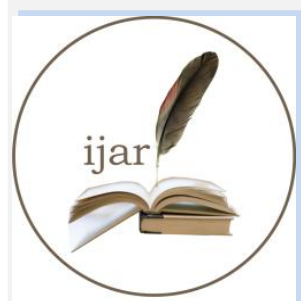

ISSN NO. 2320-5407
Journal Homepage: - www.journalijar.com INTERNATIONAL JOURNAL OF ADVANCED RESEARCH (IJAR)

Article DOI: $10.21474 / \mathrm{IJAR} 01 / 1247$

DOI URL: http://dx.doi.org/10.21474/IJAR01/1247

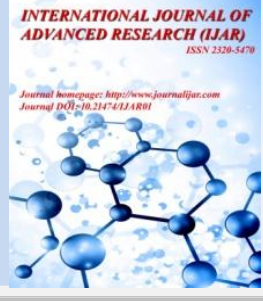

RESEARCH ARTICLE

\title{
ALARMING SUICIDAL TRENDS IN KASHMIR: AN ANALYSIS OF COVERAGE GIVEN BY THE PRINT MEDIA IN HIGHLIGHTING THE RISING SUICIDAL RATES IN THE VALLEY.
}

\section{Naseema Akhter ${ }^{1}$ and Dr.Shobh Kulshrestha ${ }^{2}$.}

1. Research Scholar, Mewar University, Gangrar, Chittorgarh (Rajasthan).

2. Research Supervisor, Vice President, Shri Venkateshvar University.

\section{Manuscript Info}

Manuscript History

Received: 12 June 2016

Final Accepted: 13 July 2016

Published: August 2016

Key words:-

Suicide, increasing, menace, newspapers, highlighting, kashmir.

\section{Abstract}

The word "Suicide" has been defined as an act or instance of taking one's life voluntarily and intentionally; the deliberate and intentional destruction of one's own life by a person; one that commits or attempts self-murder. An increasing number of suicides is an alarming situation and a matter of concern these days. It is a social evil and threat to mankind and humanity itself as a whole. Suicide estimates suggest fatalities worldwide could rise to 1.5 million by the year 2020 . Suicide is a largely preventable public health problem, causing almost half of all violent deaths as well as economic costs in the billions of dollars, says the World Health Organization (W.H.O). About 800,000 people commit Suicide worldwide every year. The southern states of Kerala, Karnataka, Andhra Pradesh and Tamil Nadu along with eastern state of West Bengal, Tripura and Mizoram have a suicide rate of greater than 16 while in the Northern States of Punjab, Uttar Pradesh and Bihar, the suicide rate is less than 4. Puducherry reported the highest suicide rate at 36.8 per 100,000 people, followed by Sikkim, Tamil Nadu and Kerala. The lowest suicide rates were reported in Bihar ( 0.8 per 100,000), followed by Nagaland, then Manipur. The print media has been widely reported as having an important role in the prevention of suicide. The print media has to play a powerful role in educating the masses about suicide prevention besides reporting on such issues. Stories about suicide can inform readers and viewers about the likely causes of suicide, its warning signs, trends in suicide rates and recent treatment advances. Media stories about individual deaths by need to be covered and can result in decreased suicide rates. Suicide is a slur on Society and even State of Jammu \& Kashmir has not been left untouched by the menace of suicides. It is not unusual to see the reports of suicides in daily newspapers. The purpose of the present study is to find out the role of newspapers in highlighting the increased suicide rates in the kashmir valley. 


\section{Introduction:-}

Suicide cases are on the rise in Kashmir with even teenagers as young as 14, attempting suicide. This issue is emerging as a major problem in the society. More than 60 percent of those who commit suicides in Kashmir are women. And it is not just teenagers but widows, half-widows of conflict and those who face domestic violence are in the high risk group of suicide committers in Kashmir. Parental pressure and Academic pressure, by expecting too much from the students by putting them under constant pressure often leads to attempted suicides. A lot of students complain of huge pressure from the family to score good marks. This pressure only increases at the time of competitive exams. For some the pressure is too much to bear and they take the extreme step.

Kashmir valley has witnessed a sharp rise in suicide cases over the past two years owing to varied reasons ranging from unemployment to marital discord. While 61 persons committed suicide in the 12 months of 2006, the figure rose up in the successive years and stands at 42 for the first five months of the current year. Experts in the field believe that the society in kashmir is faced with many issues which strengthened the tendency of suicide among the residents of the valley. The two- decade long turmoil in the Kashmir valley has also a role in the rising number of suicides herein. Violence is no way conducive to good physical and psychological growth, experts believe. An environment which is not congenial for proper physical and psychological growth leads to decrease in the levels of tolerance among human beings. Violence may not be directly responsible for suicides in Kashmir but it does create a situation whereby a person might contemplate or attempt to end his or her life. The other factors responsible for most of the suicides in the valley are failed love affairs, failure of students to meet the expectation of their parents and marital discord.

Women are far more sensitive and emotionally weak than men. They have lesser tolerance levels than men, which explain why a higher number of persons who commit suicide belong to fairer sex. Young girls mostly committed suicides due to failed love affairs. Unemployment is also a major cause behind increased suicide rates in kashmir. In kashmir the common methods of committing suicide include: Drug overdose, Hanging, Poisoning, Jumping, Wrist Slitting, Electrocution, Drowning, Pesticides etc. In urban areas hanging, jumping into rivers and consuming poison are some of the most common methods of committing suicide. In villages pesticides are often used. Women commonly set themselves ablaze during suicide attempts.

40 percent of suicides have taken place in Srinagar and Anantnag districts due to the reasons of domestic problems with minimum in Kulgam 22.5 percent says the report. In Srinagar 37.50 percent suicide cases have been reported in a decade due to the post marital discord and a minimum of 17.50 percent in Bandipora district. Suicides due to intergeneration conflicts were recorded maximum in Kupwara district i.e. 35 percent and minimum in Srinagar (12.5 percent). Suicides due to failure in examinations, have been reported maximum in Bandipora district (20 percent) and minimum in Shopian (2.5 percent).suicides due to other reasons (such as love affairs etc) have been reported maximum in District Pulwama (10 percent) and minimum in Srinagar and Ganderbal districts (2.5 percent).

The National Crime Bureau records of India states that Kashmir has a higher suicide rate than the Indian states of Utter Pradesh and Bihar, since one person in the valley commits suicide every day. Experts believe these numbers are conservative estimates, as media reports and police and hospital records do not present the real scenario of just how rampant suicide has become in Kashmir.

\section{Objective of the study:-}

- To find out the reasons behind increased suicidal rates in Kashmir and its portrayal by the newspapers.

- To find out the efforts made by the concerned government and non-government agencies to combating suicide in Kashmir.

\section{Methodology:-}

\section{Data collection strategy (primary and secondary methods):-} Interviews:-

The Researcher conducted interviews of experts like Editors and journalists of various Newspapers being published from Kashmir. Interviews of some Sociologists, Psychiatrists; Police investigating Officers etc. were also conducted to get their views and opinions on the subject at study. In the collection of data help has been sought from different medical institutions of the Valley like those of General and District Hospitals, and the other relevant organizations. An intensive study was carried out by employing the Interview Schedule and Observation as methodological tools. 
And to carry out this field study an attempt based on positivistic approach was utilized. The data collected was supplemented with the secondary data gathered from the records of the Gazetteers, Books, Research Papers, and other relevant unpublished archival material available on this subject. In order to gather the preliminary idea about the study, the researcher went for the pilot study so as to be able to design and formulate the schedule for the data collection and subsequently refine, facilitate and yield precise direction to the research. After collecting information from the field, the interview schedule was condensed and rechecked in order to put all the information in methodological order. Statistical estimations such as aggregation, percentage, etc. were made in order to present the findings precisely. The researcher conducted the interviews of experts in the field of journalism including journalists and academicians to get a clear view of present scenario of suicidal rates in Kashmir and its portrayal by the print media.

\section{Case studies:-}

In the Interview Schedule all the questions were structured, listing alternative answers. The respondents had to choose the appropriate ones according to their own judgment \&understanding. Through interview one can get more information than other methods. Besides, while interviewing the respondents, the Researcher made a keen observation of the respondents' actions and their conditions. Sources of data collection for Suicide Attempters (Case Studies).The victims who had only attempted suicide, the researcher had to take resource to a different source. The primary source of or case studies adopted by the researcher was interview and observation method. Most commonly, it was the unstructured interview which was used by the investigator. The questions were usually open ended with a conversational tone. However, at times, the structured interview was also used as part of a study. The Researcher got most of the information from the victim himself. The Researcher in most cases got into friendly conversation with the victim and sometimes used some enticement to persuade the victim into answering or getting into talking mode. Besides the victim himself some information had also to be had from the friends or relatives of the victim. Sometimes the information was also got from hospital and police reports. Afterwards the story narrated by the victim himself and the information got from the other acquaintances of the victim, coupled with the police and hospital reports \& was woven into case studies.

\section{Comparative analysis:-}

The author did a comparative analysis of five leading dailes of Kashmir valley which included: Greater Kashmir, Rising Kashmir, Kashmir Images, Srinagar Times, and The Daily Aftab. Among the five selected newspapers, Greater Kashmir, Rising Kashmir, Kashmir Images were the English dailies of Kashmir and the remaining two were the Urdu dailies. A comparison of the news reports and articles related to suicides highlighted in these newspapers was made.

\section{Case studies of suicide victims and their portrayal by the five leading newspapers of kashmir (discussion and} analysis):-

The aim of case study method was to find out the factors that account for the behaviour patterns of the given unit and its relationships with the environment. The case data was gathered with a view to search out for the causes behind the committed suicides and the coverage given by the newspapers to such incidents in five major districts of the valley viz; Srinagar, Budgam, Anantnag, Baramulla and Kupwara.

(Note: - The names used in the Case Studies have been changed, for legal and ethical reasons).

\section{Case 1:-}

\section{Background Information:-}

Age (at the time of Suicide Attempt): 21

Educational Qualification: 12th

Occupation: Student

Mode of Suicide: Poisoning

Sex: Male, Marital Status: Unmarried

District: Srinagar Demographic Status: Urban

Year of the Incident: 2010

\section{Finding:-}

Muhammad Saleem of Srinagar district was born in a lower middle class family. After passing 12th, grade he got admission in an engineering college outside the state, after paying two lakh rupees as donation. He searched for a 
suitable job in government or private sector but was unable to find a suitable job. He tried hard to get any other job but failed. Finally, he got disillusioned with life and ended his life by hanging himself. Amongst the five newspapers being selected for the study only two newspapers which included Greater Kashmir and Rising Kashmir reported this incident of suicide. In both the papers a single column story appeared on page No's 5 and 6 of the respective papers. The researcher after analyzing the newspapers of the very month could not find any follow up for the same report.

Case 2:-

Background Information:-

Age (at the time of Suicide Attempt): 16

Educational Qualification: 10th

Occupation: Student

Mode of Suicide: Jumping into River

Sex: Male, Marital Status: Unmarried

District: Srinagar Demographic Status: Urban

Year of the Incident: 2011

\section{Finding:-}

Sahil Farooq, a resident of khanyar of Srinagar district committed suicide by Jumping into the river. He was a class 10th student in SP Higher secondary Srinagar. After appearing in the final examination, he was declared fail in two subjects. He could not bear his failure in the examination and consumed poison in order to end his life. But fortunately he got the timely treatment and thus survived. After analyzing the five newspapers being selected for the study only newspaper, Greater Kashmir had reported this incident of suicide. A single column story appeared on page No 5 on the following gday after the incident. No follow up for the same report was seen.

\section{Case 3:-}

Background Information:-

Age (at the time of Suicide Attempt): 31

Educational Qualification: primary level

Occupation: Housewife

Mode of Suicide: Poisoning

Sex: Female, Marital Status: Married

District: Budgam Demographic Status: Rural

Year of the Incident: 2010

\section{Finding:-}

Saleema, 31 years old, a resident of chadoora area of District Budgam attempted suicide in the year 2010. She was beaten and tortured by her in laws to such an extent that she took poison and ended her life forever. She was survived by three daughters. On analyzing the five selected newspapers, the researcher could find that only Greater Kashmir had reported this incident of suicide the following day. No follow up for the report was seen.

\section{Case 4:-}

\section{Background Information:-}

Age (at the time of Suicide Attempt): 41

Educational Qualification: Post Graduate

Occupation: Unemployed

Mode of Suicide: Poisoning

Sex: Male, Marital Status: Unarried

District: Budgam Demographic Status: Rural

Year of the Incident: 2012

\section{Finding:-}

Basharat Ahmad, 41 years old, a resident of District Budgam consumed poison and ended his life in the year 2012. He had been a meritorious student and had achieved masters degree in science from Kashmir university. He was a sole bread earner for his family after his father's death. He tried hard to get any job but failed. Finally, he got disappointed with life and ended his life by hanging himself. On analyzing the five selected newspapers, only 
Greater Kashmir and Rising Kashmir reported this incident of suicide in the form of a single column story the following day. No follow up for the report was seen.

\section{Case 5:-}

Background Information:-

Age (at the time of Suicide Attempt): 21

Educational Qualification: 12th

Occupation: Student

Mode of Suicide: Jumping into River

Sex: Female, Marital Status: Unmarried

District: Anantnag Demographic Status: Rural

Year of the Incident: 2011

\section{Finding: -}

Nuzhat Rashid, a resident of Achabal area of Anantnag district ended her life by consuming pesticide. She was in a relationship with a boy of the same area. Her parents locked her in a room for a couple of days and stopped her for meeting her boyfriend. She could not bear this separation and consumed pesticide and hence ended her life forever. The researcher after analyzing the five newspapers being selected for the study found that that none of the papers had reported this suicidal incident.

\section{Case 6:-}

Background Information:-

Age (at the time of Suicide Attempt): 22

Educational Qualification: 12th

Occupation: Student

Mode of Suicide: Poisoning

Sex: Female, Marital Status: Unmarried

District: Anantnag Demographic Status: Rural

Year of the Incident: 2013

\section{Finding:-}

Shazia Amin, a resident of Anantnag district finished her life by consuming pesticide. She had been a meritorious student in her school and aimed to become a lawyer. Her parents forced her to become a doctor and thus due to parental pressure had to choose science as her subject. She could not make it in the common entrance examination and was forced by her parents to appear in the common entrance examination again. Due to parental pressure shazia ended her life by taking pestiside. After analyzing the five newspapers being selected for the study the rsearcher found that only one of the papers, Greater Kashmir had reported this suicidal incident in the form of a single column story on page no 6 . No follow up could be seen.

\section{Case 7:-}

\section{Background Information:-}

Age (at the time of Suicide Attempt): 35

Educational Qualification: primary level

Occupation: Housewife

Mode of Suicide: Poisoning

Sex: Female, Marital Status: Widow

District: Baramulla Demographic Status: Rural

Year of the Incident: 2013

\section{Finding:-}

Haseena, 35 years old, a resident of District Baramulla ended her life in the year 2013. Her husband was labourer by profession. They were very poor and he died of heart attack. She was forced by her in laws to leave their home and was tortured to such an extent that she took poison and finished her life. She was survived by two daughters. On analyzing the five selected newspapers, the researcher could find that and a son. None of the newspapers which were selected by the researcher for the study purpose had reported this incident. 


\section{Case 8:-}

Background Information:-

Age (at the time of Suicide Attempt): 42

Educational Qualification: Graduate

Occupation: Unemployed

Mode of Suicide: Hanging

Sex: Male, Marital Status: Married

District: Baramulla Demographic Status: Rural

Year of the Incident: 2015

\section{Finding:-}

Nazir drew a loan of Rupees five lakh from J\&K Bank to setup a poultry farm in a remote village of District Baramulla.. He mortgaged his house and the land against the loan i.e. all the property he had. He could not make a profit in this business. The interest continued to pile up and one day he was declared defaulter. One evening he consumed some poisonous substance. He was brought to hospital where doctors declared him dead. None of the newspapers which were selected for the study purpose had reported this incident.

\section{Case 9:-}

\section{Background Information:-}

Age (at the time of Suicide Attempt): 39

Educational Qualification: 12th

Occupation: Housewife

Mode of Suicide: Jumping into River

Sex: Female, Marital Status: widow

District: Kupwara, Demographic Status: Rural

Year of the Incident: 2015

\section{Finding:-}

Shamima, 39 years old, a resident of District Kupwara committed suicide in the year 2015. Her husband was shopkeeper by profession. Her husband was killed by security forces while he was returning home one evening. After the death of her husband, she was by her in laws tortured to such an extent that she took poison and finished her life. She was survived by two daughters and a son. The researcher on analyzing the five selected newspapers for the period of study, found that only Rising Kashmir had reported this incident.

\section{Case 10:-}

\section{Background Information:-}

Age (at the time of Suicide Attempt): 41

Educational Qualification: Graduate

Occupation: unemployed

Mode of Suicide: Poisoning

Sex: Male, Marital Status: Unmarried

District: Srinagar Demographic Status: Rural

Year of the Incident: 2013

\section{Finding:-}

Muhammad Ashraf of Lolab area of Kupwara district was born in a lower middle class family. After completing graduation he was the only bread earner of his family since his father had died of a heart attack. His father had taken a loan from the bank. He had mortgaged his house against the loan i.e. all the property he had. Ashraf applied for various jobs but could not find any The interest continued to pile up and one day he consumed some poisonous substance and ended his life. On analyzing the five selected newspapers for this period, only greater Kashmir had published a single column story on page No. 5. No follow up for the report could be seen.

\section{Discussion and analysis:-}

An analysis of all the case studies reveals that the people have attempted suicide because they were surrounded by such socially created circumstances that there had appeared no egress to them and as such they were driven to 
suicide. The circumstances which led the attempters of suicide to this horrible act were socially created. Even from a cursory reading of the case studies, one more thing that becomes apparent is that all the five newspapers that were selected for the study purpose have given a minimal coverage to the suicide incidents that had occurred in the five major districts of Kashmir during the five year study. It is quite evident that amongst the five selected newspapers only Greater Kashmir and Rising Kashmir have reported some incidents of suicide that too as a single column story and without any follow up. Kashmir Images, The Daily Aftab and the Srinagar Times which have a good circulation in the valley have not reported on the suicide incidents that were case studied by the researcher during the five year period of research. The Researcher also found that the suicides that happened in urban areas were reported by all these five leading dailies from Kashmir. However the suicides that were committed in the rural areas of Kashmir either got a minimal coverage or were not reported at all by any of the selected newspapers.

\section{Interviews (discussion and analysis):-}

An intensive study was carried out by employing the Interview Schedule and Observation as methodological tools. The researcher interviewed Editors and Journalists associated with different newspapers in kashmir for their experiences in covering suicides and their assessments of the impact of the print media in lowering suicide rates and the role played by media in creating awareness about suicide menace in Kashmir. The interaction with some sociologists, psychologists and social activists working in the concerned field gave the detailed insight into the problem. Besides psychiatrists working in the psychiatric and other renowned hospitals of the valley gave their views for their expertise on suicide, to discuss their perspectives on the menace and their concerns about media coverage of suicides. Station heads of various police stations also provided their perspective regarding the subject at study. Various religious scholars were also interviewed to know their role in curbing the suicide stigma.

Various psychologists, sociologists and psychiatrists have conducted numerous studies on the growing suicidal rates in Kashmir. They believe that media has a huge role and responsibility in highlighting this grave issue of suicides through their write ups and campaigns. The researcher approached the noted people in the field and asked about their views on the subject at study. The interviews thus conducted have been summed up by the researcher as following:

The renowned psychologist of Kashmir, G .A Madhosh says that the suicidal tendencies among people of Kashmir particularly youth, are indeed growing at an alarming level. He believes that people take the extreme step of ending their life to convey their sufferings. Therefore for of all it becomes necessary for a family or parents of a person to notice the behavioural changes like depression, anger if any, in their children. G.A Madhosh adds that Newspapers being the prominent medium of information in the valley has a huge role to play in highlighting the suicide menace here in. $\mathrm{He}$ is of the opinion that newspapers in the valley have reported the suicide incidents in a smaller percentage. He believes that newspapers report the suicide attempts and not the after effects of suicide. He is of the view that print media has a very little role in creating awareness about the increasing suicide trends in the Kashmir and also in suggesting its prevention.

One of the noted sociologists of valley Dr. B.A Dabla has studied the description and analysis of 27,00 acts of suicide in valley from 2009 to 2011 . According to him the apparent factors which lead to suicides include divorces, failure in exams, marital disputes. Also there are fundamental factors, basic social and economic factors involved in it. He says the beginning of the conflict in the valley has resulted in the educational backwardness, economic crises and an environment was formed which made people the victims of depression. Prof Dabla believes that media needs to play an important and serious role if suicides are to be controlled. Being an expert in the field, Prof Dabla is of the opinion that newspapers in Kashmir play a very little role in portraying this social menace. Although the newspapers in the valley report the incidents of suicides but mere reporting of suicide incidents will not help to curb this menace from the state, believes Prof Dabla. He further says that newspapers being the dominant medium of communication in the valley can play a magnificent role in creating awareness about this menace through their editorials, articles, features and can start a campaign against this deadly menace. But the newspapers in Kashmir have played a negligible part in doing so. B.A.Dabla, further says that very little role has been played by government and non-government agencies to cobat this serious issue of increasing suicides in the valley. He urges that there is immediate need to support and promote NGO's that work in the field of suicide prevention.

Dr Arshad Hussain, Professor at Department of Psychiatry, Government Medical College, Srinagar, says that each day three to four cases of suicides are reported to SMHS which means around 900 cases of suicides per year. He revealed that analytic suicide rates in valley could be as high as 13 per $1,00,000$, which is almost the suicide rate in rest of India i.e. 10.3 per 1, 00,000. Arshad Hussain says that print media being the main source of communication 
in kashmir has a huge role and responsibility in highlighting the increasing suicidal rates in the valley in order to create awareness amongst the masses in order to curb this menace from the state. He believes that most of the suicide incidents go unreported by the media especially in far flung areas of the valley. Arshad Hussain is of the opinion that newspapers in the valley should collectively start a campaign against the suicide menace through their write ups so as to curb this social menace. He adds that not only the media but also government and nongovernment agencies have to come forward to start a movement against this menace which unfortunately is lacking in Kashmir valley.

Arenowned psychiatrist of the Kashmir valley Dr. Mushtaq Margoob says that newspapers in the valley play a minimal role in highlighting the suicide menace. He believes that most of the suicide cases in the valley go unreported and the newspapers write a very little about this nuisance. He adds that increased suicidal rates in the valley is an alarming issue and needs the collective efforts of the media organizations in order to educate the people about the deadly consequences of the suicide and provide the immediate measures for its prevention. He opines that the state government have not taken any such measures as to establish the counselling centres for suicide patients in order to curb this nuisance and also non- governmental agencies should be promoted to come forward, since these Organizations are in better position to help in promoting public education about suicide they are quite successful in bringing down suicide rates.

The suicide attempts by the people get registered in the concerned police stations. The police officials say that most of the suicide attempts remain hidden from the society because of the social stigma attached with it. However the incidents which get registered in the police stations, not all of them get coverage by the newspapers.

A senior investigation officer, Basharat Ahmad, at Police Control Room Srinagar says that suicidal rate is increasing day by day with teenagers as young as 14 attempting suicide in Kashmir. He adds that out of the total number of suicide attempts committed during a year, only a few get registered in the Police station because of the social stigma attached with the suicide. He believes that the newspapers in kashmir do not publish all the suicidal incidents which get registered in the police stations. He further adds that media being the fourth pillar of a society has a huge to play a greater role in highlighting the grave issue of suicides through their write ups which can change the mind setup of the people, and thus lower the suicidal rates in the valley.

Station House Officer of Anantnag police station believes that newspapers in kashmir give a very little coverage to suicide attempts that occur in the rural areas of the kashmir valley. He says that not all the suicide attempts get registered in the police stations because people find a shame attached with the suicide. But amongst the cases which get registered in the police stations only a few get portrayed by the newspapers says the official.

Station House Officer of Budgam district showed a serious concern for the increasing suicidal rates in the district from the past few years. He narrates that the newspapers in kashmir valley highlight very little percentage of suicide attempts. He suggests that newspapers being the main source of communication in the valley should start a movement against this deadly menace through their write ups and campaigns in order to educate the masses about the dreadful consequences of the suicide.

Ishfaq Ahmad, a social activist in kashmir says that suicide menace has resulted in a huge loss of human lives in the valley from past few years. He is of the opinion that newspapers in the valley have played a very little role in highlighting this serious issue. Suicides can be prevented through serious efforts of all the newspaper organization working in the valley since it is the media which can change the mind set up of people in a particular direction through their write ups.

Throughout history, suicide has been both condemned and condoled by all the religions of the world. Suicide attempts are punishable by law in many countries. Kashmir being a Muslim dominated state; the Muftis and Imams in the valley highly condemn the suicidal activities and urge the media for imparting religious education especially to the youth of the state through their write ups in order to curb this menace from the society.

Mufti Bashir ud Din, The grand Imam of kashmir highly condemns the increasing suicides in the valley. He opines that newspapers in kashmir play a minimal role in portraying the suicide menace in the valley. He says that newspapers just report the suicide attempts that too in a smaller percentage and mere reporting of deaths will not educate the masses about the deadly consequences of committing suicide. He further adds that newspapers being an 
easily accessible medium of communication need to create an awareness about this nuisance through their articles by imparting religious values in context of increasing suicides in kashmir.

Mufti Mohdammad Isaq Nazki president Darulaloom rahimiya Bandipora district believes that increasing suicidal rates in kashmir is a grave issue in the present times and needs a serious concern from all the media groups working in the valley. He is of the view that the newspapers in the valley do not give a sufficient coverage to the rising suicide rates in the valley. He urges that media organizations need to impart religious and moral education to the masses with regard to increasing suicides in the valley in order to lower the suicide rates.

Newspapers being the dominant medium of information in kashmir can play a powerful role in educating the masses about suicide prevention besides reporting on such issues. Newspapers through their editorials and articles can inform the readers and viewers about the likely causes of suicide, its warning signs, trends in suicide rates and recent treatment advances.

Fayaz Ahmad Kaloo, the Editor of the Greater Kashmir one of the leading dailies in Kashmir says that increased suicidal rates in Kashmir valley is serious issue in the present time. He is of the view that the conflict situation in kashmir from past so many years has become the main point of attention for the print organizations working in kashmir. He adds that political instability in the valley calls for attention from all the media groups and also needs equal attention from the media organizations working in the valley. He further adds that the long turmoil and political instability in the valley needs to be addressed because such disturbances in the valley have a huge impact on the increasing suicidal tendencies amongst the masses in the valley.

Shujaat Bukhari, the Editor of the Rising Kashmir, another leading daily of kashmir says that the rise in suicide rates in kashmir is a serious issue and needs to be addressed. He adds that newspapers in kashmir report the attempted suicides which come up into their notice but most of the suicide cases especially which happen in the rural areas of the valley go unreported because the families of the victims do not want to give any details regarding the incident. He further says that the ongoing conflict in the kashmir valley calls for attention from all the newspaper organizations working in the valley. He opines that the conflict situation in the valley has resulted has also a role in the rising number of suicides herein.

Dilnaz Boga, a Mumbai based journalist working with kashmir images says that rising suicidal rates in kashmir valley is a serious issue which needs a due consideration by the newspapers being published from the valley. She adds that the prevailing situation of turmoil and political instability in kashmir makes newspapers to give maximum space to politics and conflict related issues. She says that newpapers working in the kahmir valley have their offices located at Srinagar and it becomes difficult for reports to travel to far off place to cover the suicide attempts.

Shahid wani, a senior reporter associated with the Srinagar times, a highly circulated urdu daily of kashmir says that reports associated with different newspapers have to cover their respective beats on daily basis and the suicides which come into the notice of the reports get published in the papers.

\section{Findings:-}

After collecting the data from the sources, the summary and analysis of the findings of the study is presented and the inferences have been drawn. Majority findings from this data lead the author to develop a proposition that taking into consideration number of suicides and attempts of suicide makers, the intensity of this social trend is very high in Kashmir valley. Nearly 24,000 men and women, mostly young, have attempted suicide in the last 17 years in kashmir. Of them about 3,000 have been successful and most of them were between the age of 16 and 21 . Kashmir has a higher suicide rate than the Indian states of Utter Pradesh and Bihar, since one person in the valley commits suicide every day. These numbers are conservative estimates, as media reports and police and hospital records do not present the real scenario of just how rampant suicide has become in Kashmir. The actual rate is higher than what is being reported. The researcher after conducting some case studies in the five major districts of the Kashmir valley and after analysing the five local dailies which were identified on the basis of readership, reach etc which included: Greater Kashmir, Rising Kashmir, Kashmir Images, Srinagar Times, and The Daily Aftab came across a number of findings:

The five newspapers of the valley which were selected for the study newspapers in Kashmir have failed in highlighting the grave issue of suicides as compared to other issues which find a good space in these papers. Theire 
reportage of suicide incidents has remained limited to just covering a story about a committed suicide. Most of the suicide attempts were not reported at all by some leading dailies. In Kashmir the reportage by newspapers regarding increasing suicide rates has just remained confined to publishing a story about a committed suicide that too in the form of a single column story. Newspapers in kashmir have a very little role in generating awareness about growing suicide rates in the valley through the articles, editorials and features. Although the researcher after analysing the five selected dailies for the study found a lot of campaigns started from time to time by these newspapers to highlight certain issues related to environment in the valley. But no initiatives have been taken by any of the selected newspapers in order to start a campaign against the serious issue of rising suicide rates in kashmir.

The state government has not taken the required initiatives through the media to curb the increasing suicide nuisance in kashmir. The state government just provides assistance for the up gradation of academic, clinical and diagnostic facilities at the Psychiatric Hospitals in Srinagar, but given the enormity of the problem combined with the paucity of mental health service there is an immediate need to start a movement through newspaper campaigns which the government has failed in doing so. None of the NGO's work in the field of suicide prevention in kashmir since these Organizations are in better position to help in promoting public education about suicide and are quite successful in bringing down suicide rates. The author could found only one counselling centre for the suicide patients at the Police Control Room (PCR), Srinagar where only lesser number of patients get treatment since they hesitate to visit Police control room where the counselling centre is located.

\section{Conclusion:-}

Jammu \& Kashmir is grappling with numerous issues from illiteracy to Insurgency to unemployment and other health related issues and hence, suicide is accorded low priority in the competition for meagre resources. This issue is emerging as a major problem in the society. The psychological, social and financial impact of suicide on the family and society is immeasurable. Those who attempts suicide first share it with her family or friends about the suicidal tendencies, then take the extreme step. Society in general and the parents in particular must reorient themselves to the changed circumstances so as to fight the problem. Suicide tendency patients need to be kept under the continued medical supervision. Impulse control disorders, psychiatric disorders, materialistic lifestyles, psychosocial and socio-economic problems are some of the major causes for the increase in suicides in Kashmir. "Social" causes are mostly linked to family pressure, marital status, career, strained relationships and the inability to compete at social levels. Amongst teenagers, poor impulse control, examination stress, love affairs and parental pressure are found to be prominent reasons for suicides. There should be adoption of a practical system of education, counselling and religious education as a means of prevention.

Newspapers as we know play a vital role of information dissemination to huge number of readers in order to generate awareness about different social evils prevalent in a society and their preventive measures which to a good extent leads to the elimination of such issues from the society. But mere reporting of suicidal issues as a news story will no way lead to eradication of this growing social menace from the society. The suicide attempts that occur in the urban areas of Kashmir find a good space in the newspapers. However most of the suicide attempts that happen in the rural parts of the valley go unreported because reporters have no access to such stories since all the newspapers have their offices located in Srinagar which is the main city centre of the valley. Most of the suicide cases do not get registered in the police stations because of the social stigma attached with it. Newspapers through their write-ups, editorials and features could generate a huge awareness about the suicide stigma and its consequences on the lives of the victims and their families. But a negligible percentage of articles portraying the suicide nuisance get published in the newspapers which are being published from the valley.

The newspapers in the valley can collectively start a campaign against the deadly menace of suicide through their write ups which they have failed to do so. However these papers have given a good coverage to other issues portraying politics, conflict, health, education, environment and etc. No, doubt such issues also need a due consideration but at the same time increasing suicidal rates in the Kashmir valley has become an alarming issue and calls for serious attention from all the media organizations working in the valley. For this the role of the newspapers comes to play first and foremost because it is the media which can transform a society by generating awareness about the social stigmas prevalent in a society which will help in the eradication of social evils like suicide from the society.

Reducing suicide requires a collective, concerted effort from all groups in the society. It high time for Jammu \& Kashmir Government to initiate a Mental Health Programme which involves reducing the availability of and access 
to pesticides, reducing alcohol availability and consumption, promoting responsible media reporting of suicide and related issues, promoting and supporting NGOs, involving religious leaders, improving the capacity of primary care workers and specialist mental health services and providing support to those bereaved by suicide, providing psychiatric evaluation and treatment to people who have attempted suicide, training teachers, police officers and practitioners of alternative system of medicine and faith healers. All these steps can help to mitigate the problem of suicides in Jammu and Kashmir.

\section{Acknowledgement:-}

The author is very grateful to Dr. Shobha Kulshrestha, a dedicated researcher in areas of Mass Communication, for providing the excellent guidance and tactical advice with great dedication and interest. I sincerely express my indebtedness and deep sense of gratitude to her for the invaluable guidance and many useful suggestions.

I would take this opportunity to offer my special thanks to Mr. Ishfaq Ahmad who has always been a source of strength and inspiration for me. I greatly acknowledge him for contributing useful suggestions, encouragement, assistance and input which have had a significant impact on the final structure of this work.

\section{References:-}

1. Margoob MA (2002) A Pilot study of Psychiatric morbidity in the community in Kashmir valley.

2. DablaBA.Suicides in Kashmir valley- A report by the department of sociology University of Kashmir Nov 2000.

3. Margoob MA A study of present magnitude of psychiatric disorders and existing treatment services in Kashmir Nov 2000.

4. Albany, N. Y. 1984. Suicide among School Age Youth. The State Education Department of the University of the State of New York.

5. Aleem, Shamin. 1994. The Suicide: Problems and Remedies, Ashish Publishing House, New Delhi.

6. Farberow, Norman L. 1980. The Many Faces of Suicide: Indirect Self-Destructive Behaviour. New York:McGraw-Hill.

7. Menninger, Karl A. 1985. Man against Himself, Harcourt Brace Jovanovich: New York.

8. Thompson, Kenneth, 1994. Readings from Emile Durkheim, Routledge London.

9. Williams, J. M. G. \& Pollock, L. R. 2000. The Psychology of Suicidal Behaviour, In International Handbook of Suicide and Attempted Suicide eds K. Hawton \& K. Van Heeringen

10. Accidental Deaths and suicides in India. National Crime Records Bureau. Ministry of home affairs. Government of India. 2007.

11. Bagadia VN, Ghadiali HN, Shah LP. Unemployment and attempted suicide. Indian J Psychiatry. 1976;18:1319.

12. Vijayakumar L. Suicide in India in suicide in Asia. In: Yip PS, editor. Hong Kong Univ Press; 2008.pp. 121-31.

13. FEKETE, S., A. SCHMIDTKE, E. ETZERSDORFER, 1998. Media reports on suicide in Hungary, Austria, Germany and Lithuania in 1981 and 1991. Suicide Prevention. D. DeLeo, A. Schmidtke \& r.f.w. Diekstra, Eds. Kluwer Academic Publishers. Leiden.

14. MICHEL, K., C. FREY, K. WYSS, 2000. An exercise in improving suicide reporting in print media. Crisis 21: $1-10$.

15. LITTMAN, S.K. 1985. Suicide and suggestibility-the role of the press. Am. J. Psychiatry 124: 156-160.

16. World Health Organisation (WHO), authors Preventing Suicide: A Resource for Media Professionals. WHO; Geneva, Switzerland: 2000.

17. Reporting on Suicide: Recommendations for the Media Prevention Resource Center; Waltham, MA, USA: 2001.

18. Motto J.A. Newspaper influence on suicide: A controlled study.Arch. Gen. Psychiiatry. 1970;23:143-148.

19. Media Guidelines for Reporting Suicide and Self-Harm. Samaritans; Stirling, UK:2008. 